\title{
The experimental approach into the influence of external inductance on the discharge characteristic of HiPIMS
}

\author{
Saeed Ghasemi ${ }^{1} \cdot$ Pourya Seyfi $^{1} \cdot$ Alireza Farhadizadeh $^{1} \cdot$ Hamid Ghomi $^{1}$
}

Received: 30 April 2019 / Accepted: 31 August 2019 / Published online: 17 September 2019

(c) The Author(s) 2019

\begin{abstract}
The main objective of the current paper is to describe the effect of external inductance (EI) on the current discharge waveforms of HiPIMS at different pulse-on time $\left(P_{\text {on }}\right)$ and its relation with static deposition rate and topographical properties of deposited titanium thin films, which is investigated by scanning electron microscope and atomic force microscope. It has shown that the higher the EI, independent of the $P_{\text {on }}$, the higher the peak power is. The delay time also extensively increases when an EI is implemented into the circuit. However, the rise time does not have a linear dependency with the EI and its behavior changes to some extent at different $P_{\text {on }}$. By increasing the EI from zero to $30 \mathrm{mH}$ at $P_{\text {on }}=60 \mu \mathrm{s}$, the peak power subsequently rises from 11 to $32 \mathrm{~kW}$ at constant time-average power. Meanwhile, the deposition rate decreases from 8.5 to $1.5 \mathrm{~nm} / \mathrm{min}$, which is mainly attributed to the metal ions return to the target surface and nonlinear dependency of sputtering yield with applied voltage. It was also revealed that the higher peak power has no special effect on the surface roughness of titanium thin films deposited by HiPIMS.
\end{abstract}

Keywords Deposition rate $\cdot$ External inductance $\cdot$ HiPIMS $\cdot$ Surface roughness

\section{Introduction}

Magnetron sputtering (MS) is one of the most common methods to fabricate a variety of thin films with specific properties appropriate for industrial applications [1-7]. Unbalanced magnetron sputtering (UMS) and closed field unbalanced magnetron sputtering (CFUMS) are a step forward of classical MS in which they provide higher deposition rate, denser and more spacious plasma expanded to the substrate while the quality of thin films is also enhanced $[6,8,9]$. The enhancement of thin films quality is strongly connected to the ratio of the ion to atom transported into the substrate $[10,11]$, in which they not only have enough kinetic energy to be located on the thermodynamically lower energy place but also they can kick off loosely bonded atoms from the substrate surface, providing the negative bias voltage is applied. Although an advantage of such mentioned methods is to lack micron-size droplets [12-14], which is prevalent in cathodic arc physical vapor

Hamid Ghomi

h-gmdashty@sbu.ac.ir

1 Laser and Plasma Research Institute, Shahid Beheshti University, Evin, Tehran 1983963113, Iran deposition (CAPVD), the deposition rate and the amount of ionization rate are inferior to that of CAPVD method. Much research has been carried out to improve the ionization rate of plasma and the deposition rate of coatings in the MS system [15-20]. High-power impulse magnetron sputtering (HIPIMS) has recently attracted much interest owing to its capability to deposit droplet-free coatings with a high degree of ionization in the plasma that is desirable for some films [21, 22]. The high ionization is of interest because it gives rise to dense coatings as well as good adhesion on the substrate [23]. Therefore, many researchers worldwide have been motivated to fully exploit the features of this method [24-28].

The current waveforms in HiPIMS are a fingerprint of the system, indicating the ionization rate of Ar, gas sputtering, self-sputtering, metal ionization, waves, and instabilities, and it has been covered in the literature under different conditions [29-32]. For instance, in Mclain's work [33] who studied the deposition rate of HiPIMS with respect to the arrangement of magnets, the shape of the current waveforms of HiPIMS, correspondingly with the plasma confinement nearby the cathode, has altered from runaway to plateau, resulting in distinct deposition rate. In another work by Zuo et al. [34], the current waveforms for a variety of target 
materials are discussed in which all have some humplike shape with distinct peak current that is related to the secondary electron emission yield. In another paper [35], the target current at different reactive gas pressures is considered, demonstrating the higher the gas pressure, the higher the peak current reaches. The correlation between the peak current in HiPIMS with the microstructure of coatings was explored by Alami et al. [36]; when the high peak current is achieved, the density and surface roughness of deposited films changed, whereas the deposition rate tremendously reduced. Additionally, the crystallinity of the films decreased so that no XRD peaks were finally detected. They reasoned that the high ionization rate in higher peak current leads to more ions reaching to the substrate, changing the films morphology. This is also reported by [36] that the ion-toatom ratio near the substrate increased around 3 times when the peak current changed from 113 to $185 \mathrm{~A}$. The current waveforms for different target materials showed that the peak current value and the current plateau are corresponding with the rarefaction (or sputter wind) and ionization rate of metals, respectively [37]. The comparison of the current waveforms of HiPIMS and 1.0 A-DC-superimposed HiPIMS is indicative of the higher peak current in HiPIMS while the slope of the current exceeds for DC-HiPIMS [38]. Revel et al. [39] have theoretically and experimentally investigated the effect of an external circuit with a given resistance on the current waveforms of HiPIMS. They observed that the lower external series resistor leads to the higher current plateau.

Despite the many studies on the features of current waveforms, the effect of an EI on the properties of current waveforms of HiPIMS has not been explored. Therefore, in this work, the influence of an EI on the current waveforms and static deposition rate and topographical properties of deposited titanium is addressed.

\section{Experimental procedure}

The experiments were carried out in a home-made vacuum deposition system that is described elsewhere [40]. The HiPIMS system was also designed and fabricated in our laboratory. The power supply of HiPIMS has capabilities to produce pulses with $P_{\text {on }}$ and frequency in the range of 20-500 $\mu$ s and $100-1500 \mathrm{~Hz}$, respectively. A DC power supply (1-1000 V and $1 \mathrm{~A})$ was used to support the HiPIMS power, in which the maximum target voltage and current could increase up to $1000 \mathrm{~V}$ and $100 \mathrm{~A}$, respectively.

The electric scheme of HiPIMS system is shown in Fig. 1. A DC power supply charges the Cs capacitor bank (storage capacitor). The energy stored in the capacitor bank is dissipated into the plasma using the ultrafast switch. The pulse width modulator (PWM) determines on and off the timing of switch in pulses of well-defined width and frequency. A series resistor R3 of $3 \mathrm{ohms}$ is employed to limit the discharge current. In order to study the effect of EI on discharge characteristics of HiPIMS discharge, a variable inductance in series with cathode is implemented as L1 in Fig. 1 in which its value alters from 0 to $70 \mathrm{mH}$.

During experiments, the average power was set to $250 \mathrm{~W}$ by regulating the value of voltage. The effect of the variable inductance on HiPIMS discharge characteristics was studied at a frequency of $500 \mathrm{~Hz}$ and five values of $P_{\text {on }}$ in the range of 60-300 $\mu$ s. The amount of EI had different values of 0,5 , $10,20,30,40,50,60$, and $70 \mathrm{mH}$. The other experimental parameters such as duty cycle, working pressure, gas flow ratio are rendered in Table 1.

The voltage was measured at two points: point A, which includes the summation of inductor and magnetron sputtering and point $\mathrm{B}$, which includes only magnetron sputtering. One should note that the average power is calculated based

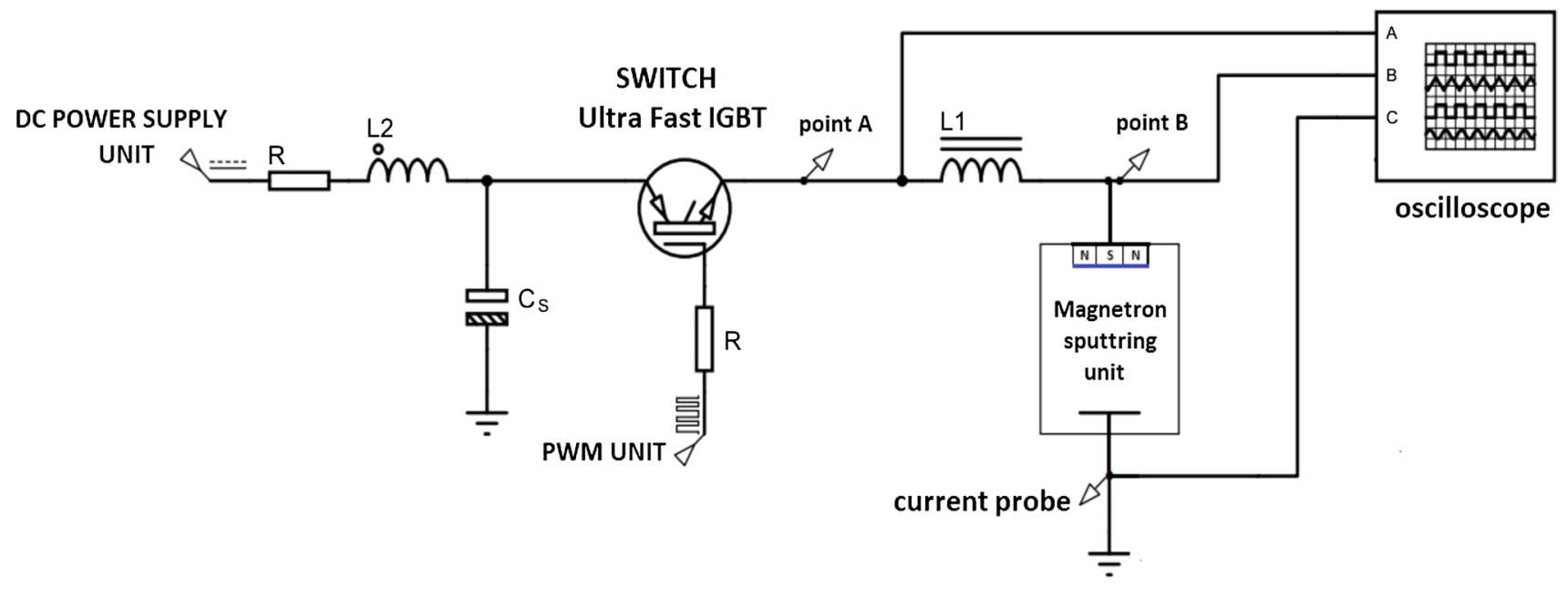

Fig. 1 The electric circuit of the HiPIMS system 
Table 1 The parameters for titanium thin films deposition and evolution of current waveforms

\begin{tabular}{lll}
\hline Parameters & Ti deposition & Current waveforms \\
\hline Target to substrate distance & $9 \mathrm{~cm}$ & - \\
Bias voltage & $-100 \mathrm{~V}$ & - \\
Base pressure & $5 \times 10^{-5} \mathrm{Torr}$ & - \\
Average power & $250 \mathrm{~W}$ & $250 \mathrm{~W}$ \\
Pressure & $5 \mathrm{mTorr}$ & $5 \mathrm{mTorr}$ \\
Substrate temperature & $250{ }^{\circ} \mathrm{C}$ & - \\
Frequency & $500 \mathrm{~Hz}$ & $500 \mathrm{~Hz}$ \\
Duty cycle $(\%)$ & 3 & $3,5,7.5,10,15$ \\
\hline
\end{tabular}

on the voltage of point A, assuming the energy loss in the inductor is negligible. The deposition parameters of titanium thin films and those relating to extracting evolution of current waveforms data are also listed in Table 1. The topography of deposited thin films was evaluated by atomic force microscopy (AFM) in contact mode (park scientific instrument-CP auto probe). Field emission scanning electron microscope (FESEM) was also used to measure the film thickness so that the static deposition rate [41] is calculated.

\section{Results and discussion}

\section{Current waveforms}

In this part, the current waveforms at different EI and $P_{\text {on }}$ are discussed (Fig. 2). In Fig. 2a, the current evolution for EI equal to $0,5,30$, and $60 \mathrm{mH}$ at $60 \mu$ s is plotted. When the EI is zero, as it is a normal HiPIMS circuit, the current after a short time (delay time) goes up for about $10 \mu \mathrm{s}$ and it reaches to steady state, named current plateau. Finally, it sharply drops to a little negative and stays close to zero until it turns on again, which is marked as pulse-off time. When an EI is implemented into the external circuit, the current waveform is extremely changed. As seen in the beginning, the current shows a transient peak and then it remains constant and positive near to zero that can be labeled as the delay time. The delay time, here, is extended due to the
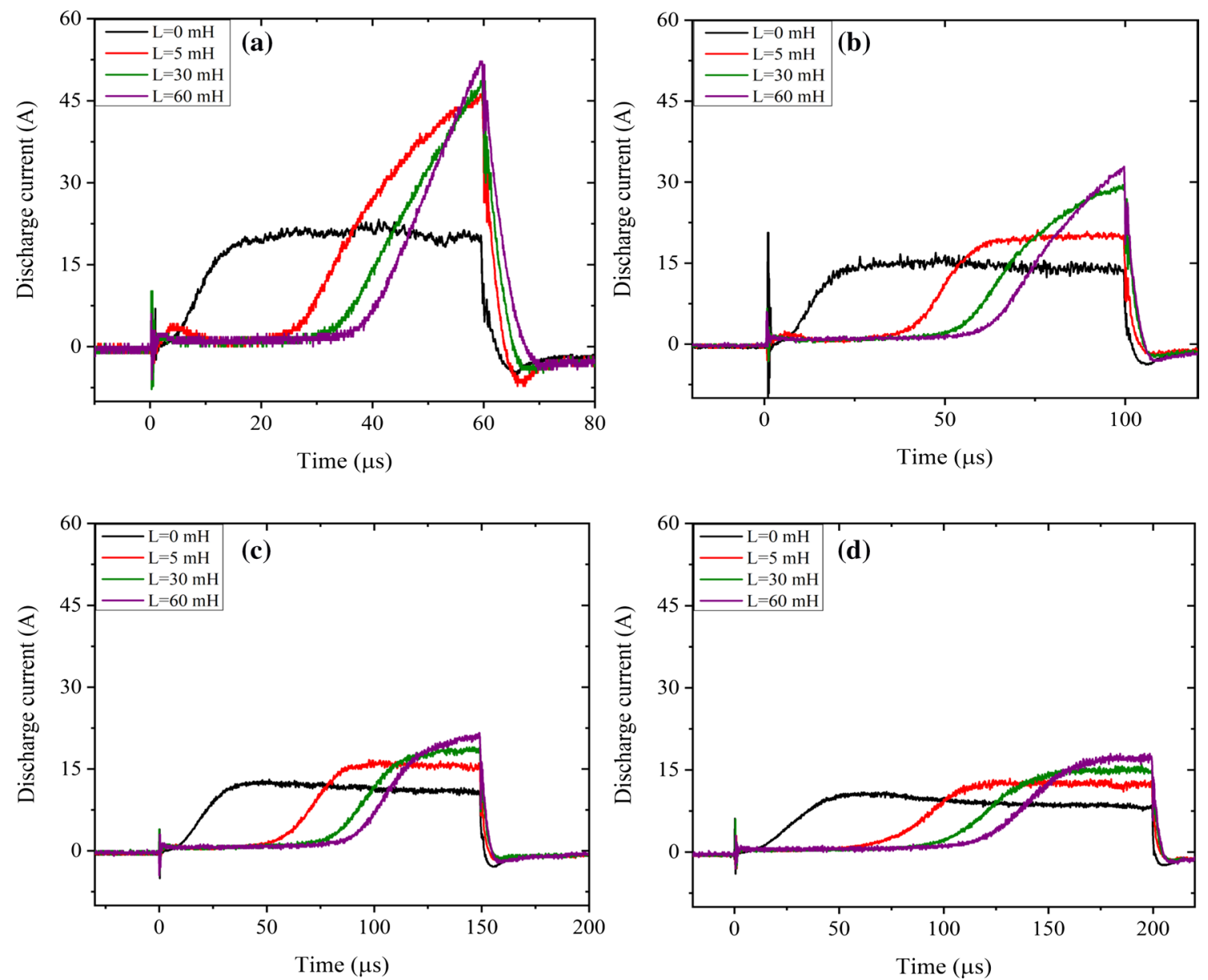

Fig. 2 The current waveforms for different EI where $P_{\text {on }}$ is $\mathbf{a} 60 \mu \mathrm{s}$, b $100 \mu \mathrm{s}, \mathbf{c} 150 \mu \mathrm{s}$, and d $200 \mu \mathrm{s}$ 
inductance phenomena. After around $25 \mu \mathrm{s}$ up to $40 \mu \mathrm{s}$, which is dependent on the value of EI, the current starts to increase more or less sharply to a specific value of current around $50 \mathrm{~A}$ (Fig. 2a) and then falls too sharply to below zero when the pulse ends and it stays negative for some microseconds. The description of other current waveforms at different $P_{\text {on }}$ is very similar to that of $P_{\text {on }}=60 \mu \mathrm{s}$. However, in Fig. $2 \mathrm{~b}$, when the $\mathrm{EI}$ is equal to $5 \mathrm{mH}$, the current after a delay time goes to plateau phase while for the higher EI, not only the delay time lasts longer, but also the plateau disappeared and it seems the current is somehow transient. In other words, when the $P_{\text {on }}$ is quite short (60 $\left.\mu \mathrm{s}\right)$, or the EI is relatively high, the current plateau is not observed and the peak current is at the end of the pulse, implying the current is transient. In Fig. 2c, when the $P_{\text {on }}$ is $150 \mu$ s, the transient current is only observed for EI equal to $60 \mathrm{mH}$ and for lower EI, the current plateau is reached. When the $P_{\text {on }}$ increases to $200 \mu \mathrm{s}$ (Fig. 2d), even at high EI, the current plateau is
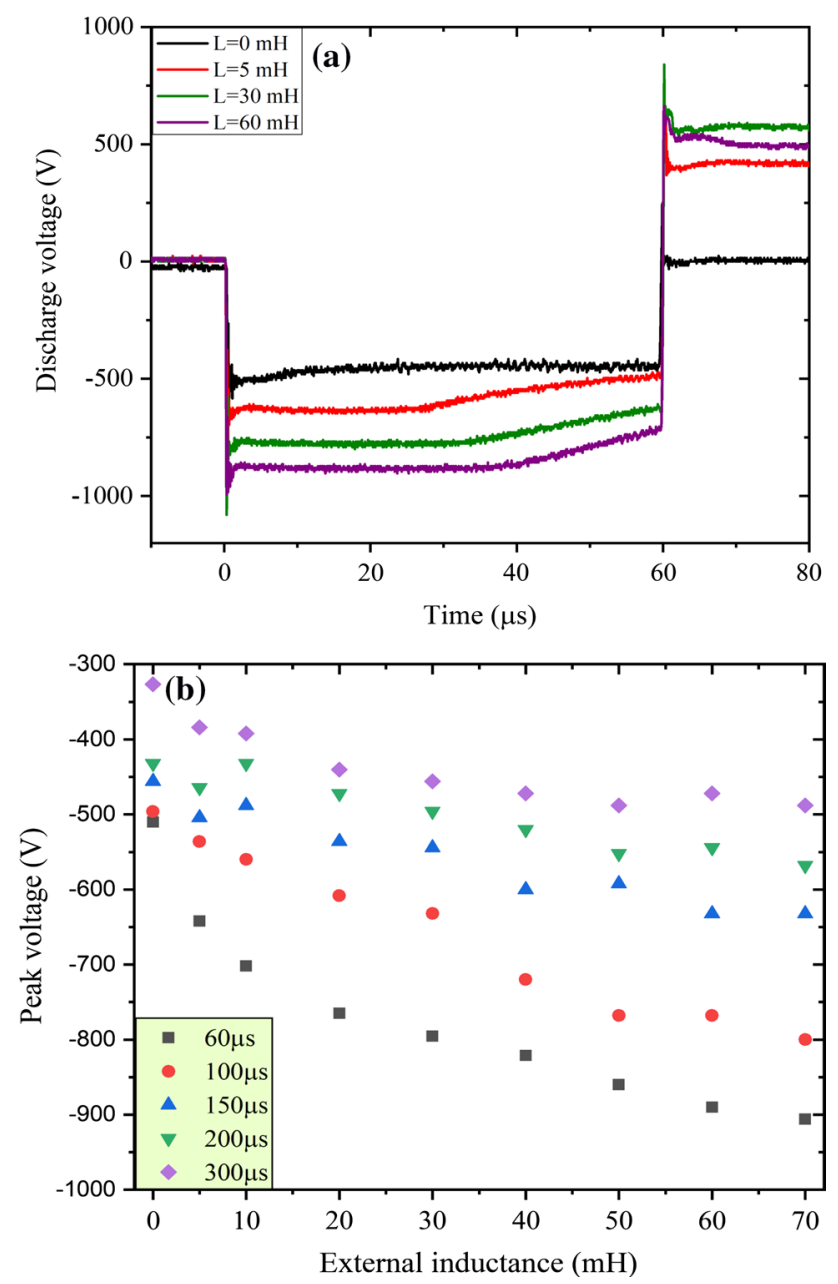

Fig. 3 a The applied voltage (point A in Fig. 1) shape for $P_{\text {on }}=60 \mu \mathrm{s}$, b and the peak voltage for different EI and $P_{\text {on }}$ observed that is originated from the lower applied voltage so that the time-average power remains constant.

As it was stated in the experimental section, the voltage is measured at points A and B (Fig. 1). The voltage at point A for $P_{\text {on }}=60 \mu$ s is represented in Fig. 3a. As seen, the voltage shape is squared, however, after the delay time when the current starts to increase sharply (Fig. 2a), the voltage drops and it continues decreasing as long as the current rises. It is such a normal phenomenon that the value of voltage decreases when the sputtering turns on, i.e., the impedance of the system decreases when the current begins to rise and the decline of applied voltage occurs that is also observed here [42]. Figure $3 \mathrm{~b}$ depicts the peak voltage in terms of EI at a variety of $P_{\mathrm{on}}$. The general trend for applied voltage is easily perceived so that the higher the EI, the higher the value of applied voltage (point A) is. In addition, when the $P_{\text {on }}$ increases, the applied voltage reduces. One should note that the time-average power in all data is constant and equal
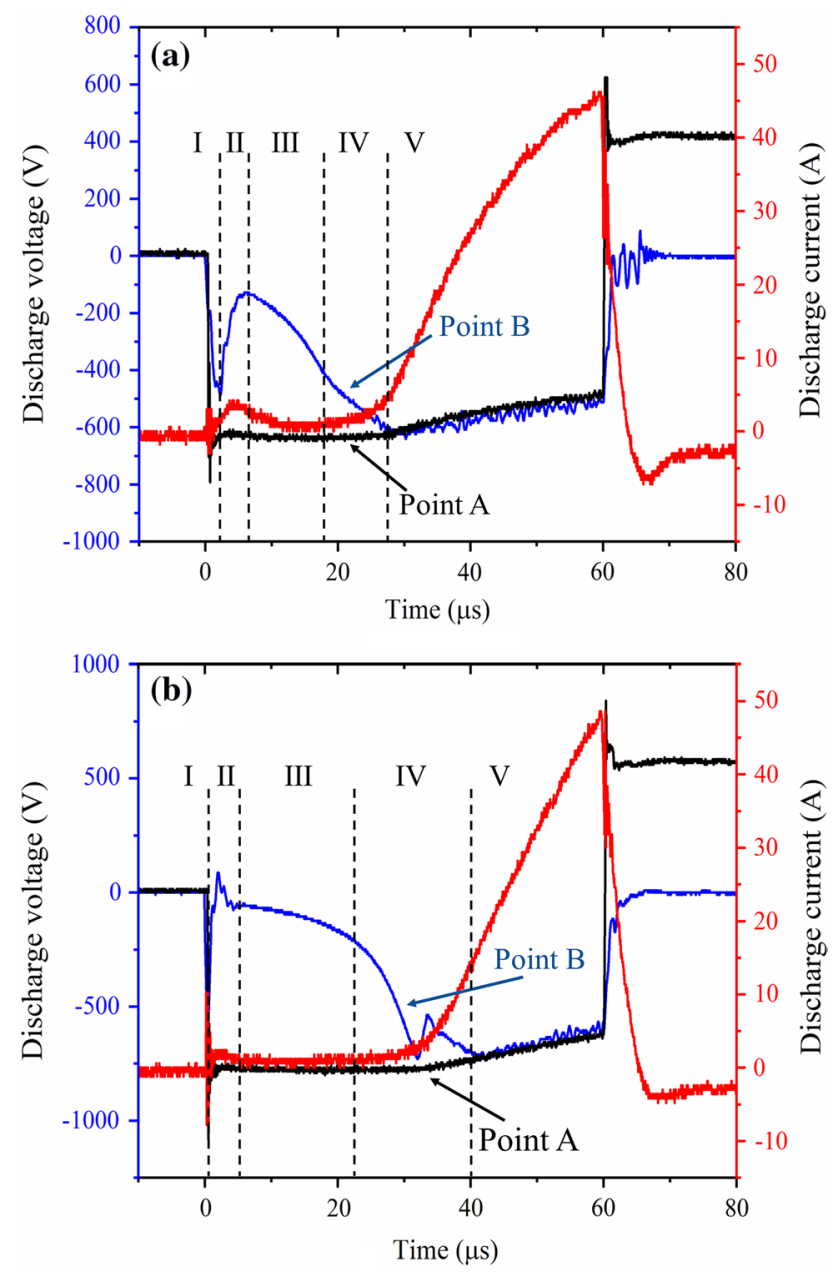

Fig. 4 The current waveforms and the voltage (A and B in Fig. 1) at $P_{\text {on }}=60 \mu$ s for $\mathbf{a} \mathrm{EI}=5 \mathrm{mH}$ and $\mathbf{b} \mathrm{EI}=30 \mathrm{mH}$ 
to $250 \mathrm{~W}$; the voltage is regulated in a way to reach the given power. It is the reason why the longer duration of $P_{\text {on }}$, results in lower current and voltage.

Since the voltage at point B (Fig. 1) is essential for describing the current waveforms, in particular, the beginning transient peak and extended delay time, it is measured and depicted in Fig. 4. The shape of this voltage is different from the voltage at point A owing to the EI effect. That is here discussed in detail. For the sake of simplicity, the voltage B shape is divided into five different phase at $P_{\text {on }}=60 \mu \mathrm{s}$ with $\mathrm{EI}=5 \mathrm{mH}$ (Fig. 4a). Part I: At the very beginning, since there is no current flowing through the inductor, the applied voltage at point $B$ suddenly drops to such a value similar to voltage A. Part II: As soon as the current rises or the discharge takes place, the inductor reacts to the current flow and based on the Lens law, decreases the voltage B. Since the voltage drops at point $\mathrm{B}$, the discharge becomes terminated. Part III: The current decays and the value of voltage start to increase gently. Part IV: The increasing behavior of voltage causes the current to increase slowly. Part V: Finally, after a delay time around $30 \mu \mathrm{s}$, the inductor is saturated and the current rises as there was no inductance in the circuit that is proven by equality of voltages $\mathrm{A}$ and $\mathrm{B}$. It is worth mentioning that this shape of voltage $\mathrm{B}$ is very similar to other $P_{\text {on }}$ at $\mathrm{EI}=5 \mathrm{mH}$. However, when the EI is increased to $30 \mathrm{mH}$ (Fig. 4b), the voltage shape somehow varies. One difference is about part II, in which the voltage drop is sharper and more than the latter one $(E I=5 \mathrm{mH})$.

According to the current waveforms in Fig. 2, the peak current, the rise time, and the delay time for different $P_{\text {on }}$ and EI are shown in Fig. 5. Besides, the peak power is also calculated and is shown in this figure. Figure 5a presents the peak current with respect to EI for different $P_{\text {on }}$. The highest peak current belongs to the $P_{\text {on }}=60 \mu \mathrm{s}$ and as $P_{\text {on }}$ increases, the peak current declines. One should note that the increase of EI leads to a higher peak current that is also consistent with peak power. However, for the $P_{\text {on }}=60 \mu \mathrm{s}$, using $\mathrm{EI}=5 \mathrm{mH}$ increases the peak current and the peak power around two times in compression with no EI. When EI increased to $10 \mathrm{mH}$, the increase of the peak current is not noticeable and the peak current increases very gently with respect to the EI. However, the increase of peak
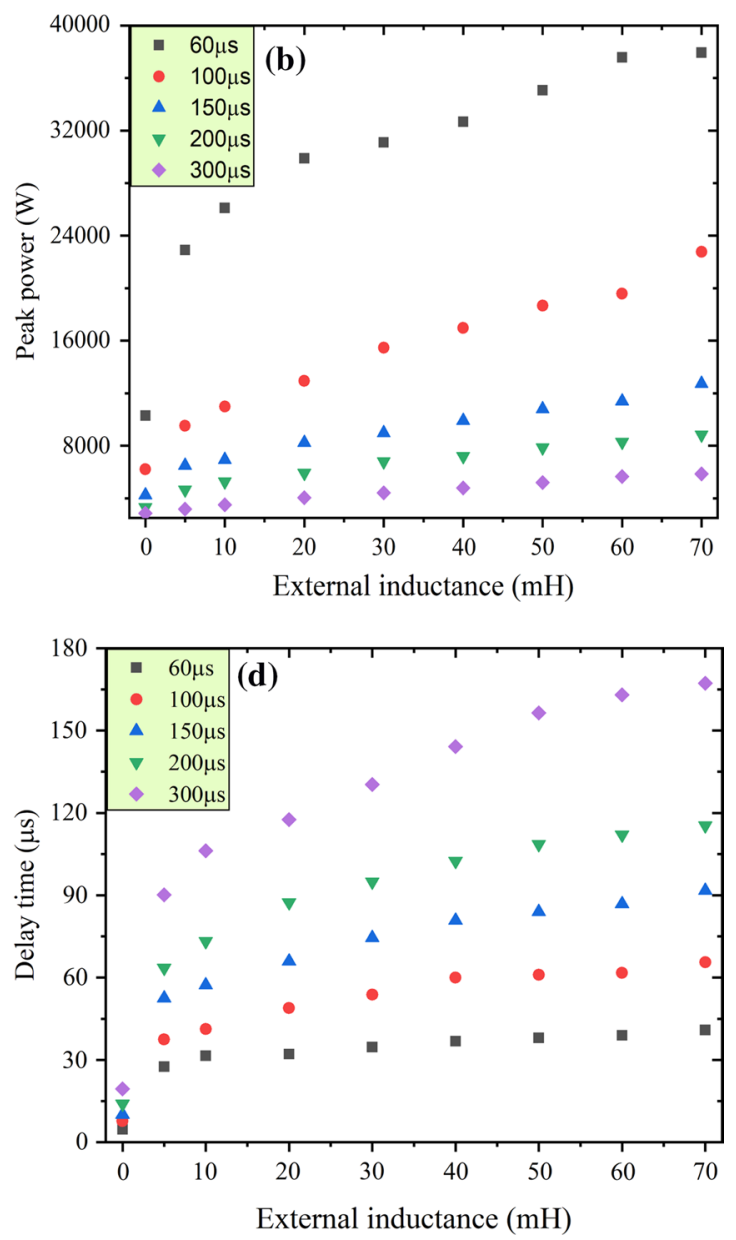

Fig. 5 The effect of EI at a variety of $P_{\text {on }}$ on the a peak current, $\mathbf{b}$ peak power, $\mathbf{c}$ rise time, $\mathbf{d}$ delay time 
power for the $P_{\text {on }}=60 \mu$ s is more considerable than the respective peak current. For the other $P_{\text {on }}$, the increasing trend of peak current and peak power with EI is very similar.

The rise time graph (Fig. 5c) exhibits that the longer the $P_{\text {on }}$, the longer the rise time is. However, the variation of rising time with EI is not well defined. Figure $5 \mathrm{~d}$ shows that the increase of EI and $P_{\text {on }}$ leads to longer delay time. When the EI is stronger, it absorbs more energy to allow the current passes through and consequently, the delay time becomes longer. As the applied voltage is lower for the higher $P_{\text {on }}$, the time for core saturation of inductor is longer and the delay time is extended.

\section{Thin films properties}

In this section, the deposition rate and surface roughness of Ti deposited layers are discussed.

\section{Deposition rate}

The deposition rate referred as static deposition rate [41] is such an important industrial parameter that is calculated here as the thickness divided by the deposition time, assuming the density of films is equal to bulk. The SEM cross section image of layers is shown in Fig. 6. It is obvious that the thickness of layers, equivalently the deposition rate, decreases as the higher EI is set on the circuit (Fig. 7), which is derived on the higher peak current (power and higher applied voltage). Note that although the peak current can be used as a factor to compare different HiPIMS system, the peak power is a better choice since it is indicative for energy that is conserved in the system. As the peak power increases, the temperature of electrons also rises, leading to the higher ionization rate and the more likely; the multiply charged metal ions are formed. The multiply charged ions are less likely to escape the negative target potential and they probably will return to the target, causing self-sputtering, and as a result, it may lower the deposition rate. As stated by Anders [41], the deposition rate at the substrate is proportional to the voltage squared. If the average power is constant, increasing the voltage results in lower deposition rate due to yield effects of sputtering species. Hence, the ratio of power-normalized rate is formulated as $\rho=k^{-0.5}$, where $k$ is the ratio of two selected voltages and $\rho$ is the factor that the deposition rate is reduced. Here, for EI equals zero and $30 \mathrm{mH}$, the voltage is -500 and $-800 \mathrm{~V}$, respectively. This
Fig. 6 The SEM cross section of Ti thin film deposited on silicon with $P_{\text {on }}=60 \mu$ s at a $\mathrm{EI}=0$, b $\mathrm{EI}=2.5 \mathrm{mH}, \mathbf{c} \mathrm{EI}=5 \mathrm{mH}$, and d $\mathrm{EI}=30 \mathrm{mH}$
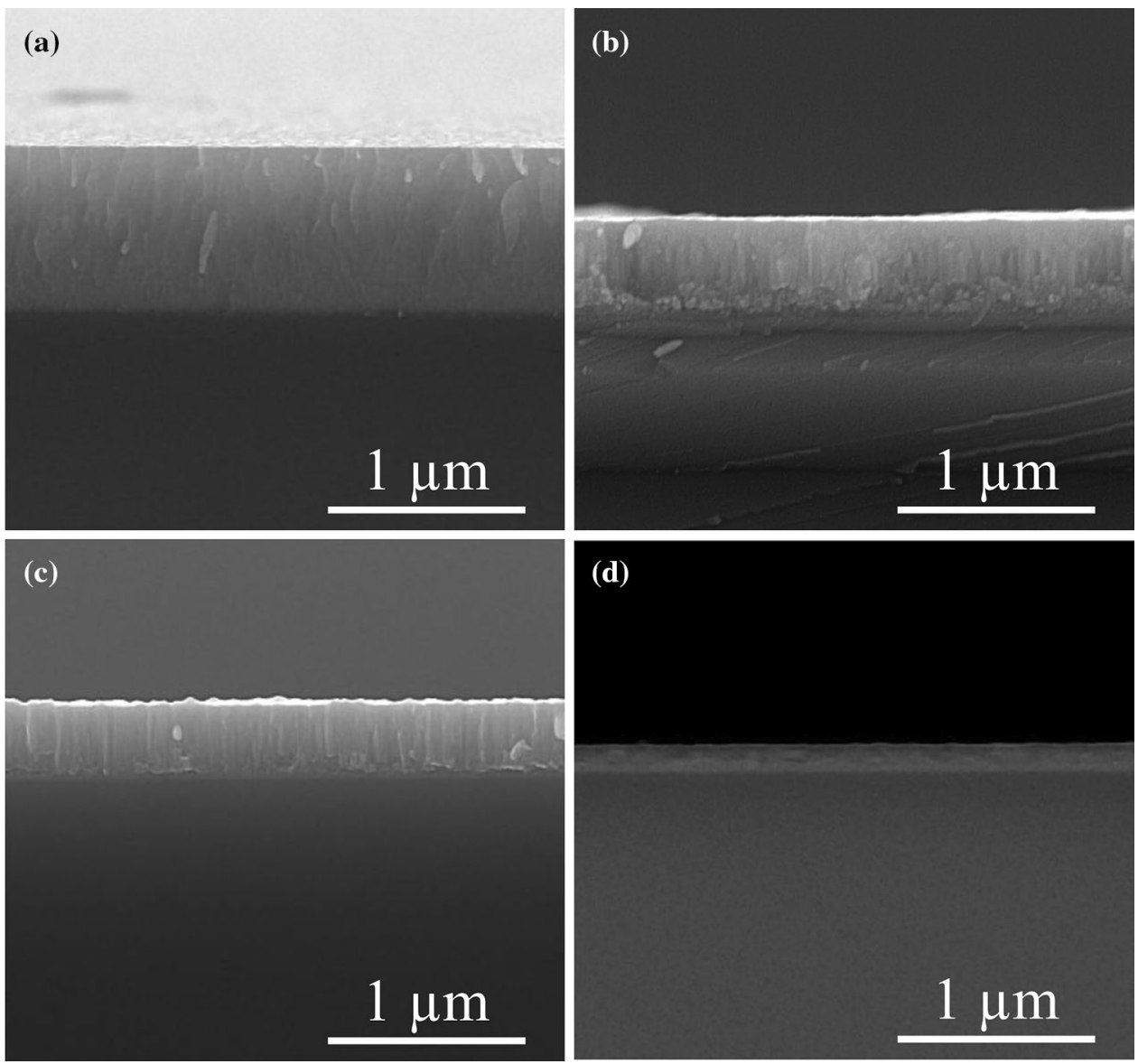


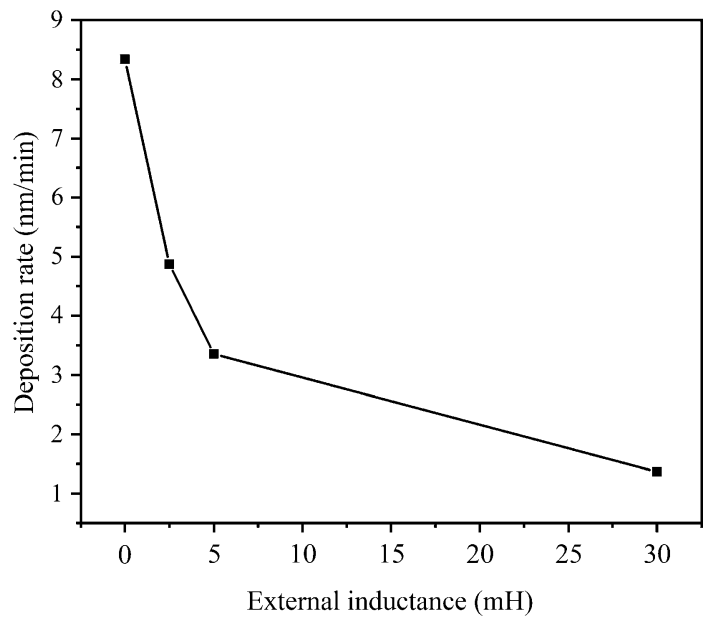

Fig. 7 The deposition rate of Ti thin films on silicon at $P_{\text {on }}=60 \mu \mathrm{s}$ with respect to EI

gives rise to $\rho=\left(\frac{800}{500}\right)^{-0.5}=0.79$, i.e., a decrease in deposition rate around $21 \%$ is related to yield effects.

\section{Surface roughness}

The topography of the surface is of high prominence in most application. There are many roughness parameters to describe the surface features. Here, the two most common parameter including average roughness $(\mathrm{Sa})$ and root mean square $(\mathrm{Sq})$ is used to evaluate the surface. The three-dimensional surface images, as well as the histogram of four samples deposited with $P_{\text {on }}=60 \mu$ s at different EI, are shown in Fig. 8. As seen, no meaningful changes in the topography of the surface are traced. The Sa and Sq are also plotted with respect to EI, showing no dependency on the EI value or the respective peak current (Fig. 9). The roughness of the surface in sputtering is highly dependent on the energy of atoms and ions reaching the substrate surface. Regardless of using an EI in the circuit, the plasma in HiPIMS consists of a high ratio of ions to atoms comparing to DC-magnetron sputtering. Consequently, the ratio of ions to neutral atoms in the vicinity of the substrate surface is considerable. Since a negative voltage bias is applied to the substrate surface, the ions can be accelerated into the surface with enough kinetic energy to fill the valley of the surface and make the shadowing effect negligible. Since the HiPIMS method, regardless of the value of peak power, can produce a significant amount of ions, it seems logical that the value of $\mathrm{Sa}$ and $\mathrm{Sq}$ shows no noticeable variation with respect to EI and peak power.

\section{Conclusion}

This study aimed to uncover the effect of an external inductance (EI) in the HiPIMS circuit on the evolution of current waveforms and the respective topographical and static deposition rate of titanium thin films. The obtained results are provided here: (a)

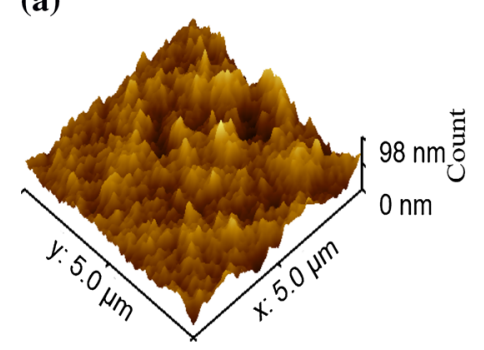

(c)

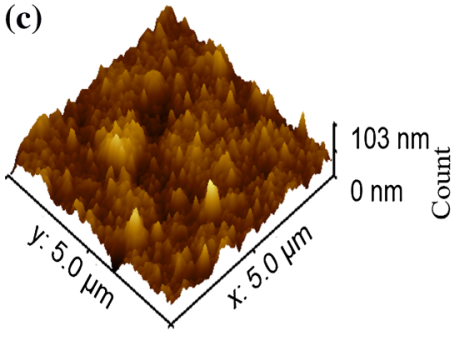

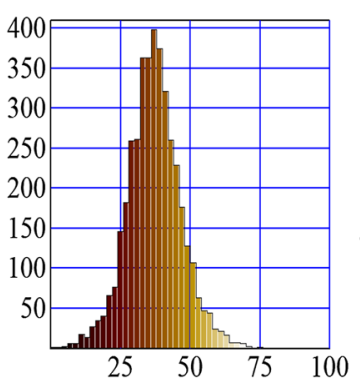

(b)

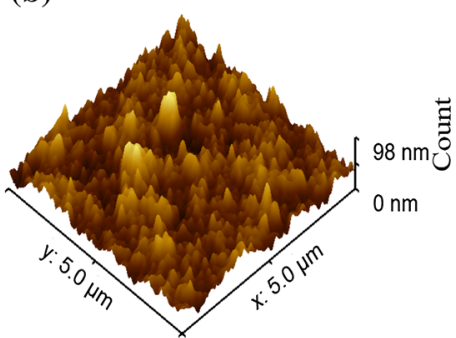

(d)

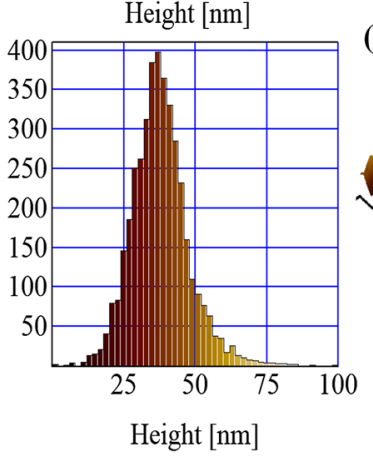

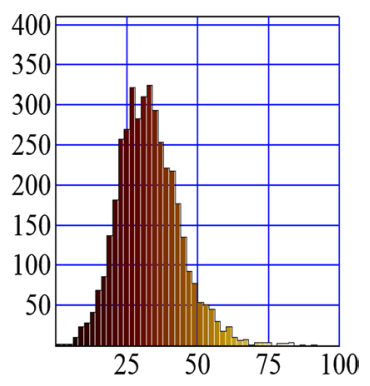

Height $[\mathrm{nm}]$

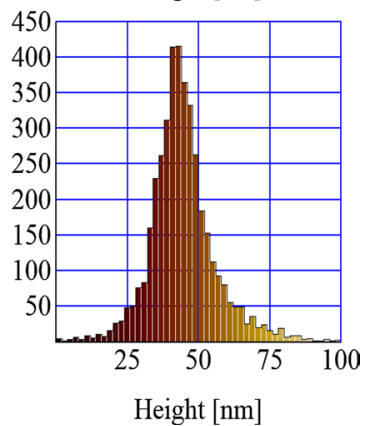

Fig. 8 The topography and histogram of deposited titanium thin films with $P_{\text {on }}=60 \mu$ s at a EI $=0, \mathbf{b} \mathrm{EI}=2.5 \mathrm{mH}, \mathbf{c} \mathrm{EI}=5 \mathrm{mH}$, and $\mathbf{d} \mathrm{EI}=30 \mathrm{mH}$ 


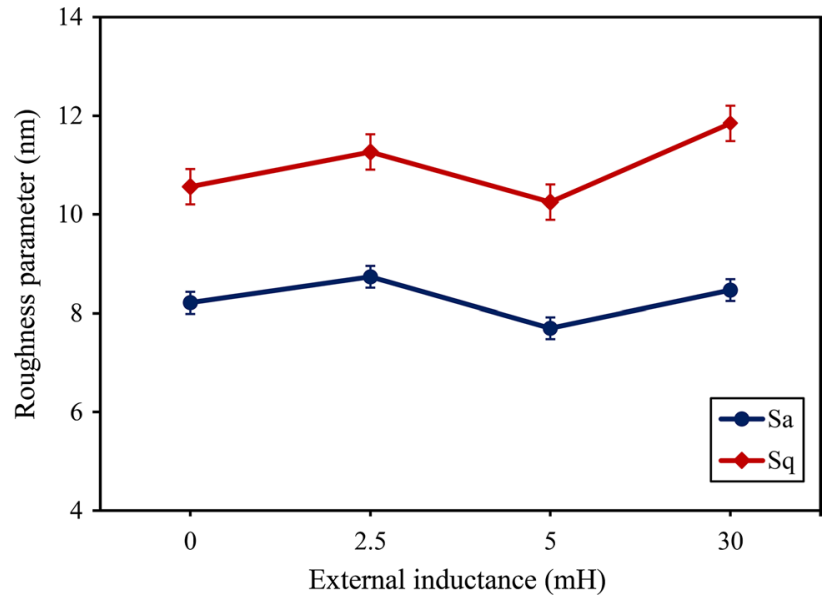

Fig. 9 The arithmetic average roughness (Sa) and root mean square $\left(S_{\mathrm{q}}\right)$ of deposited titanium thin films with $P_{\text {on }}=60 \mu$ s at different EI

(a) When the higher EI was implemented into the HiPIMS circuit or the lower pulse-on time $\left(P_{\text {on }}\right)$ was set, the peak power and the peak current increased. Note that the time-average power remained constant in all experiments and that is the reason why the peak current increased when the duration of pulse decreased. Furthermore, when the higher EI is used, the more extended delay time appears, and it means that the real on time of the pulse decreased, leading to a higher peak current and power.

(b) When the value of EI increased from 0 to $30 \mathrm{mH}$, the peak power went up from 11 to $32 \mathrm{~kW}$, whereas the deposition rate decreases from 8.5 to $1.5 \mathrm{~nm} / \mathrm{min}$ which it stems from the higher return of metal ions into the cathode and the nonlinear dependency of sputtering yield of target with the voltage.

(c) The variation of EI did not influence the surface topography that could be related to the high amount of ionization in HiPIMS regardless of EI; i.e., the large ratio of ion to atom in HiPIMS leads to the ions with sufficient energy transported to the substrate surface and overcoming the possible shadowing effect. Hence, the more increasing of ion to atom ratio does not change relatively the surface roughness.

Open Access This article is distributed under the terms of the Creative Commons Attribution 4.0 International License (http://creativeco mmons.org/licenses/by/4.0/), which permits unrestricted use, distribution, and reproduction in any medium, provided you give appropriate credit to the original author(s) and the source, provide a link to the Creative Commons license, and indicate if changes were made.

\section{References}

1. Baptista, A., Silva, F., Porteiro, J., Míguez, J., Pinto, G., Fernandes, L.: On the physical vapour deposition (PVD): evolution of magnetron sputtering processes for industrial applications. Procedia Manuf. 17, 746-757 (2018)

2. Alami, J., Maric, Z., Busch, H., Klein, F., Grabowy, U., Kopnarski, M.: Enhanced ionization sputtering: a concept for superior industrial coatings. Surf. Coat. Technol. 255, 43-51 (2014). https ://doi.org/10.1016/j.surfcoat.2013.11.040

3. Paulitsch, J., Schenkel, M., Zufraß, T., Mayrhofer, P.H., Münz, W.-D.: Structure and properties of high power impulse magnetron sputtering and DC magnetron sputtering $\mathrm{CrN}$ and TiN films deposited in an industrial scale unit. Thin Solid Films 518(19), 5558-5564 (2010)

4. Alexeeva, O., Fateev, V.: Application of the magnetron sputtering for nanostructured electrocatalysts synthesis. Int. J. Hydrogen Energy 41(5), 3373-3386 (2016)

5. Solov'ev, A.A., Sochugov, N.S., Oskomov, K.V., Rabotkin, S.V.: Investigation of plasma characteristics in an unbalanced magnetron sputtering system. Plasma Phys. Rep. 35(5), 399-408 (2009). https://doi.org/10.1134/s1063780x09050055

6. Nakao, S., Yukimura, K., Ogiso, H., Nakano, S., Sonoda, T.: Effects of Ar gas pressure on microstructure of DLC films deposited by high-power pulsed magnetron sputtering. Vacuum $\mathbf{8 9}$, 261-266 (2013). https://doi.org/10.1016/j.vacuum.2012.07.004

7. Biswas, B., Purandare, Y., Hovsepian, P.E., Khan, I.: Study of coating defects and their influence on corrosion and tribological properties of HIPIMS deposited CrN/NbN coatings. In: 60 th Annual Technical Conference Proceedings Providence, Rhode Island, Apr 29-May 4 (2017). https://doi.org/10.14332/svc17 .proc. 42827

8. Dai, H.Y., Cheng, X.R., Wang, C.F., Xue, Y.C., Chen, Z.P.: Structural, optical and electrical properties of amorphous carbon films deposited by pulsed unbalanced magnetron sputtering. Opt. Int. J.Light Electron Opt. 126(7-8), 861-864 (2015). https ://doi.org/10.1016/j.ijleo.2015.02.047

9. Kelly, P.J., Arnell, R.D.: Development of a novel structure zone model relating to the closed-field unbalanced magnetron sputtering system. J. Vac. Sci. Technol. A Vac. Surf. Films 16(5), 2858-2869 (1998). https://doi.org/10.1116/1.581432

10. Byon, E., Oates, T.W., Anders, A.: Coalescence of nanometer silver islands on oxides grown by filtered cathodic arc deposition. Appl. Phys. Lett. 82(10), 1634-1636 (2003)

11. Anders, A., Anders, S., Brown, I.G.: Transport of vacuum arc plasmas through magnetic macroparticle filters. Plasma Sources Sci. Technol. 4(1), 1 (1995)

12. Lattemann, M., Ehiasarian, A., Bohlmark, J., Persson, P., Helmersson, U.: Investigation of high power impulse magnetron sputtering pretreated interfaces for adhesion enhancement of hard coatings on steel. Surf. Coat. Technol. 200(22-23), 6495-6499 (2006)

13. Lin, J., Moore, J.J., Sproul, W.D., Mishra, B., Wu, Z., Wang, J.: The structure and properties of chromium nitride coatings deposited using dc, pulsed dc and modulated pulse power magnetron sputtering. Surf. Coat. Technol. 204(14), 2230-2239 (2010). https://doi.org/10.1016/j.surfcoat.2009.12.013

14. Hovsepian, P.E., Sugumaran, A.A., Purandare, Y., Loch, D.A.L., Ehiasarian, A.P.: Effect of the degree of high power impulse magnetron sputtering utilisation on the structure and properties of TiN films. Thin Solid Films 562, 132-139 (2014). https://doi. org/10.1016/j.tsf.2014.04.002

15. Hopwood, J.: Ionized physical vapor deposition of integrated circuit interconnects. Phys. Plasmas 5(5), 1624-1631 (1998) 
16. Rossnagel, S., Hopwood, J.: Metal ion deposition from ionized mangetron sputtering discharge. J. Vac. Sci. Technol. B Microelectron. Nanometer Struct. Proces. Meas. Phenom. 12(1), 449-453 (1994)

17. Rossnagel, S., Hopwood, J.: Magnetron sputter deposition with high levels of metal ionization. Appl. Phys. Lett. 63(24), 32853287 (1993)

18. Wang, W., Foster, J., Wendt, A.E., Booske, J.H., Onuoha, T., Sandstrom, P.W., Liu, H., Gearhart, S.S., Hershkowitz, N.: Magnetic-field-enhanced $\mathrm{rf}$ argon plasma for ionized sputtering of copper. Appl. Phys. Lett. 71(12), 1622-1624 (1997)

19. Rezek, J., Vlček, J., Houška, J., Čapek, J., Baroch, P.: Enhancement of the deposition rate in reactive mid-frequency ac magnetron sputtering of hard and optically transparent $\mathrm{ZrO}_{2}$ films. Surf. Coat. Technol. 336, 54-60 (2018)

20. Sidelev, D.V., Bleykher, G.A., Krivobokov, V.P., Koishybayeva, Z.: High-rate magnetron sputtering with hot target. Surf. Coat. Technol. 308, 168-173 (2016)

21. Burcalova, K., Hecimovic, A., Ehiasarian, A.P.: Ion energy distributions and efficiency of sputtering process in HIPIMS system. J. Phys. D Appl. Phys. (2008). https://doi.org/10.1088/00223727/41/11/115306

22. Hála, M., Zabeida, O., Baloukas, B., Klemberg-Sapieha, J.E., Martinu, L.: Time- and species-resolved plasma imaging as a new diagnostic approach for HiPIMS discharge characterization. IEEE Trans. Plasma Sci. 38(11), 3035-3039 (2010). https://doi. org/10.1109/tps.2010.2064183

23. Ehiasarian, A.P., Wen, J.G., Petrov, I.: Interface microstructure engineering by high power impulse magnetron sputtering for the enhancement of adhesion. J. Appl. Phys. 101(5), 054301 (2007). https://doi.org/10.1063/1.2697052

24. Hecimovic, A., von Keudell, A., Schulz-von der Gathen, V., Winter, J.: Various shapes of plasma spokes observed in HiPIMS. IEEE Trans. Plasma Sci. 42(10), 2810-2811 (2014). https://doi. org/10.1109/tps.2014.2330454

25. West, G., Kelly, P., Bradley, J.: A comparison of thin silver films grown onto zinc oxide via conventional magnetron sputtering and HiPIMS deposition. IEEE Trans. Plasma Sci. 38(11), 3057-3061 (2010)

26. Oliveira, J.C., Ferreira, F., Anders, A., Cavaleiro, A.: Reduced atomic shadowing in HiPIMS: role of the thermalized metal ions. Appl. Surf. Sci. 433, 934-944 (2018)

27. Li, G., Sun, J., Xu, Y., Xu, Y., Gu, J., Wang, L., Huang, K., Liu, K., Li, L.: Microstructure, mechanical properties, and cutting performance of TiAlSiN multilayer coatings prepared by HiPIMS. Surf. Coat. Technol. 353, 274-281 (2018)

28. Hovsepian, P.E., Ehiasarian, A., Purandare, Y., Mayr, P., Abstoss, K., Feijoo, M.M., Schulz, W., Kranzmann, A., Lasanta, M., Trujillo, J.: Novel HIPIMS deposited nanostructured CrN/NbN coatings for environmental protection of steam turbine components. J. Alloys Compd. 746, 583-593 (2018)

29. Anders, A., Andersson, J., Ehiasarian, A.: High power impulse magnetron sputtering: current-voltage-time characteristics indicate the onset of sustained self-sputtering. J. Appl. Phys. 102(11), 113303 (2007). https://doi.org/10.1063/1.2817812

30. Gudmundsson, J.T., Brenning, N., Lundin, D., Helmersson, U.: High power impulse magnetron sputtering discharge. J. Vac. Sci. Technol. A Vac. Surf. Films 30(3), 030801 (2012). https://doi. org/10.1116/1.3691832

31. Wu, Z., Xiao, S., Ma, Z., Cui, S., Ji, S., Tian, X., Fu, R.K., Chu, P.K., Pan, F.: Discharge current modes of high power impulse magnetron sputtering. AIP Adv. 5(9), 097178 (2015)

32. Huo, C., Lundin, D., Raadu, M.A., Anders, A., Gudmundsson, J.T., Brenning, N.: On the road to self-sputtering in high power impulse magnetron sputtering: particle balance and discharge characteristics. Plasma Sources Sci. Technol. 23(2), 025017 (2014). https://doi.org/10.1088/0963-0252/23/2/025017

33. McLain, J., Raman, P., Patel, D., Spreadbury, R., Uhlig, J., Shchelkanov, I., Ruzic, D.: Linear magnetron HiPIMS high deposition rate magnet pack. Vacuum 155, 559-565 (2018)

34. Zuo, X., Chen, R., Ke, P., Wang, A.: Gas breakdown and discharge formation in high-power impulse magnetron sputtering. IEEE Trans. Plasma Sci. 47(2), 1215-1222 (2019)

35. Rabotkin, S., Oskirko, V., Ionov, I., Semenov, V., Shipilova, A., Solovyev, A.: Process stabilization during reactive high power impulse magnetron sputtering of $\mathrm{Ce} / \mathrm{Gd}$ target. In: Journal of Physics: Conference Series 2018, vol. 3, p. 032078. IOP Publishing

36. Alami, J., Sarakinos, K., Uslu, F., Wuttig, M.: On the relationship between the peak target current and the morphology of chromium nitride thin films deposited by reactive high power pulsed magnetron sputtering. J. Phys. D Appl. Phys. 42(1), 015304 (2008)

37. Moens, F., Konstantinidis, S., Depla, D.: The target material influence on the current pulse during high power pulsed magnetron sputtering. Front. Phys. 5, 51 (2017)

38. Zuo, X., Chen, R., Liu, J., Ke, P., Wang, A.: The influence of superimposed DC current on electrical and spectroscopic characteristics of HiPIMS discharge. AIP Adv. 8(1), 015132 (2018)

39. Revel, A., Minea, T., Costin, C.: 2D PIC-MCC simulations of magnetron plasma in HiPIMS regime with external circuit. Plasma Sources Sci. Technol. 27(10), 105009 (2018)

40. Ghasemi, S., Farhadizadeh, A.R., Amadeh, A.A., Ghomi, H.: Structural and morphological properties of TiN deposited by magnetron sputtering. Surf. Topogr. Metrol. Prop. 6, 045003 (2018)

41. Anders, A.: Deposition rates of high power impulse magnetron sputtering: physics and economics. J. Vac. Sci. Technol. A Vac. Surf. Films 28(4), 783-790 (2010). https://doi. org/10.1116/1.3299267

42. Anders, A.: Tutorial: reactive high power impulse magnetron sputtering (R-HiPIMS). J. Appl. Phys. 121(17), 171101 (2017)

Publisher's Note Springer Nature remains neutral with regard to jurisdictional claims in published maps and institutional affiliations. 